\title{
Resistant Hypertension: A Comprehensive Overview
}

\section{Jacob C Jentzer ${ }^{1}$, Omar Batal', Shivdev Rao' ${ }^{1}$ and Aref Rahman ${ }^{2 *}$}

${ }^{1}$ Cardiology Fellow, Heart and Vascular Institute, University of Pittsburgh Medical Center, USA

${ }^{2}$ Assistant Professor of Medicine, Heart and Vascular Institute, University of Pittsburgh Medical Center, Director, Cardiac Catheterization Lab, VA Pittsburgh Healthcare System, USA

\begin{abstract}
Hypertension is a common, undertreated disease and a major risk factor for cardiovascular, cerebrovascular and renal disease. As many as $20-30 \%$ of hypertensive patients have resistant hypertension, defined as uncontrolled blood pressure despite 3 or more antihypertensive drugs including a diuretic, typically combined with a calcium-channel blocker and an angiotensin-converting enzyme inhibitor or angiotensin receptor blocker. Patients with resistant hypertension can often be controlled by adding a mineralocorticoid receptor antagonist and/or vasodilating beta-blocker. A significant number of patients will have a treatable secondary cause of resistant hypertension such as obesity, sleep apnea, renal insufficiency, primary aldosteronism or renal artery stenosis. For patients whose hypertension is refractory to preferred antihypertensives, use of third-line antihypertensives such as sympatholytics or vasodilators may be effective but consideration should be given to investigational device-based antihypertensive therapies. Renal artery angioplasty/ stenting can be useful in selected cases of renal artery stenosis, while renal sympathetic denervation holds promise for resistant essential hypertension.
\end{abstract}

Keywords: Hypertension; antihypertensive drugs; Antagonist; vasodilators

\section{Introduction}

Hypertension (HTN) is the most common cardiovascular disease and remains a major risk factor for coronary heart disease, cerebrovascular disease, heart failure and renal failure [1,2]. Fewer than half of patients with HTN in the United States reach their Blood Pressure (BP) goals despite availability of numerous inexpensive generic Antihypertensive Drugs (AHDs) [1,3]. Approximately 5-10\% (up to 20-30\%) of patients with inadequately-controlled HTN have resistant HTN, defined as BP that remains above goal despite optimal doses of 3 AHDs including a diuretic [4,5]. Resistant HTN includes patients whose BP is controlled on $\geq 4$ AHDs but excludes patients whose BP is uncontrolled on a suboptimal AHD regimen or $<3$ AHDs [4]. Recent studies suggest that the prevalence of resistant HTN may be increasing over time [5]. Predictors of inadequately-controlled BP that characterize resistant HTN patients include older age, obesity, higher systolic BP, diabetes, Left Ventricular Hypertrophy (LVH), and Chronic Kidney Disease (CKD) [4]. Patients with resistant HTN are at elevated risk for adverse cardiovascular outcomes, particularly stroke and hospitalization for heart failure [6]. In this review, we discuss the evaluation and medical management of resistant HTN and describe investigational device-based techniques for management of resistant HTN.

\section{Investigation of Uncontrolled HTN}

The first step in the assessment of patients with inadequatelycontrolled HTN is exclusion of falsely-elevated BP readings or lifestyle factors impairing AHD response ("pseudoresistant" HTN) (Figure 1). Poor BP measurement technique, particularly an undersized BP cuff, can falsely elevate BP readings [1]. "White-coat HTN" describes patients whose in-office BP remains elevated despite controlled ambulatory $\mathrm{BP}$, and occurs in at least $20-30 \%$ of patients with apparently resistant HTN $[7,8]$. Patients with white-coat HTN typically lack target organ damage and appear to have lower cardiovascular risk than patients with sustained HTN [9]. Ambulatory BP measurement can establish the diagnosis of white-coat HTN, and is appropriate for the evaluation of most patients with uncontrolled BP [4].
After confirming elevated BP, correctible lifestyle factors that impair BP control should be identified and ameliorated (Figure 1) [1,4]. Weight loss and increased physical activity can produce independent and potentially additive BP reductions [10-13]. Excess dietary sodium intake is common in resistant $\mathrm{HTN}$, and dietary sodium restriction can improve HTN control [4,14-16]. The Dietary Approaches to Stop Hypertension ("DASH") diet can improve BP beyond sodium restriction alone [1,15]. Smoking cessation and moderation of alcohol intake can further improve BP control [1]. A number of prescription and nonprescription drugs can elevate BP, most notably Non-Steroidal Anti-Inflammatory Drugs (NSAIDs) [1,4]. Finally, AHD adherence is critically important for adequate BP control, although lack of AHD adherence accounts for relatively few cases of resistant HTN $[4,17,18]$.

\section{Medical Treatment of Uncontrolled HTN}

The recommended 3-drug AHD regimen in patients with resistant HTN consists of maximum doses of a long-acting Thiazide Diuretic (TD), Calcium-Channel Blocker (CCB) and Angiotensin-Converting Enzyme (ACE) inhibitor or Angiotensin-II Receptor Blocker (ARB) $[4,19]$. Patients whose AHD regimen differs significantly from this combination should be switched if possible (Figure 1). Any long-acting ACE inhibitor or ARB is acceptable, but valsartan may have superior BP lowering at maximum dose [20]. Amlodipine is a useful longacting CCB given its safety and efficacy in large HTN trials [21-23]. Hydrochlorothiazide (HCTZ) is commonly available in combination AHD pills, but the longer-acting and more potent TDs chlorthalidone

*Corresponding author: Aref Rahman, MD, FACC, FSCAI, Assistant Professo of Medicine, Heart and Vascular Institute, University of Pittsburgh Medical Center Director, Cardiac Catheterization Lab, VA Pittsburgh Healthcare System, USA, E-mail: rahmanam@upmc.edu

Received January 24, 2013; Accepted March 26, 2013; Published March 28 2013

Citation: Jentzer JC, Batal O, Rao S, Rahman A (2013) Resistant Hypertension: A Comprehensive Overview. J Hypertens 2: 111. doi:10.4172/2167-1095.1000111

Copyright: (c) 2013 Jentzer JC, et al. This is an open-access article distributed under the terms of the Creative Commons Attribution License, which permits unrestricted use, distribution, and reproduction in any medium, provided the original author and source are credited. 
and indapamide are superior for BP lowering and cardiovascular prevention [22-28]. Low HCTZ doses (12.5-25 mg daily) show an inferior antihypertensive effect when compared to HCTZ $50 \mathrm{mg}$ daily or chlorthalidone $12.5-25 \mathrm{mg}$ daily [24,29]. We suggest switching HCTZ to chlorthalidone (25-50 mg daily) or indapamide (up to 2.5-5 mg daily) prior to diagnosing resistant $\operatorname{HTN}[4,19,26]$. A recent study showed a 29/12 mmHg BP reduction from substituting chlorthalidone $50 \mathrm{mg} \pm$ amlodipine $10 \mathrm{mg}$ (with or without adding aliskiren $300 \mathrm{mg}$ ) in patients whose $\mathrm{BP}$ was uncontrolled on spironolactone + another diuretic \pm another CCB [30].

\section{Investigation of Resistant HTN}

Biochemical testing in patients with resistant HTN includes measurement of serum electrolytes, urinalysis, BUN, creatinine, and fasting glucose and lipids [1,4]. Measurement of Plasma Renin Activity (PRA) and Serum Aldosterone Concentration (SAC) on a fasting morning blood sample to calculate an aldosterone-to-renin ratio (ARR, i.e. SAC divided by PRA) is recommended to screen for Primary Aldosteronism (PA) in most patients [4]. A screening electrocardiogram is appropriate to identify LVH [1]. Renal artery imaging and/or nocturnal polysomnography can be considered to screen for Renal Artery Stenosis (RAS) and Obstructive Sleep Apnea (OSA), as discussed below. Confirming dietary sodium intake with a 24-hour urine collection for sodium and creatinine can be useful in selected patients. Screening for uncommon secondary causes of HTN such as pheochromocytoma, Cushing syndrome, hyperparathyroidism, thyroid disease, aortic coarctation or intracranial tumor should be performed when there is clinical suspicion (Table 1) [4]

\section{Secondary HTN and Resistant HTN}

A significant number of patients will have a treatable secondary cause of resistant HTN, the most common being obesity, CKD, OSA, RAS and PA (Table 1) [4]. Identification and treatment of secondary causes of HTN should improve BP control and in some cases may even normalize BP without the need for AHDs. Important clues suggesting a secondary cause of HTN include severe or resistant HTN, age $<30$ years without risk factors for HTN (or HTN onset before puberty), accelerating or malignant $\mathrm{HTN}$, new onset $\mathrm{HTN}$ at age $>55$ years and refractory hypokalemia (Table 2). The common secondary causes of HTN (RAS, PA, OSA, CKD, obesity) are more prevalent in elderly patients, while the suspicion for uncommon secondary causes of HTN may be higher in young patients (Table 1) [31]. One study reported that $12.7 \%$ of patients $\geq 50$ years old with resistant HTN had a secondary cause of HTN [31]. The prevalence of secondary causes in resistant
HTN could increase as the population ages, and the most common secondary etiology underlying resistant HTN remains unclear $[31,32]$.

Obesity may be one of the most common contributors to resistant HTN [10]. Studies have identified OSA in up to $64-83 \%$ of patients with resistant HTN, making it perhaps the most common secondary cause of HTN [32-35]. Obesity and OSA directly promote resistant HTN via sympathetic activation and aldosterone-mediated sodium retention; sodium retention may be both a cause and consequence of OSA [36-39]. Screening for OSA using nocturnal polysomnography is appropriate in many patients with resistant HTN, especially those with obesity, snoring, witnessed apneas or daytime sleepiness. Weight loss and exercise are critically important for patients with obesity and resistant HTN, and gastric bypass is a viable treatment for hypertensive patients with severe obesity [11-13]. Treatment of OSA using Continuous Positive Airway Pressure (CPAP) can improve BP control in resistant HTN [40].

PA may be present in up to $17-23 \%$ of patient with resistant HTN and is suggested by hypokalemia, which occurs in fewer than half of cases [41-44]. An elevated ARR (>20-30 ng/dl per $\mathrm{ng} / \mathrm{ml} / \mathrm{h}$ ), especially with serum aldosterone concentration (SAC) $>15 \mathrm{ng} / \mathrm{ml}$, is suggestive but not diagnostic of PA and requires confirmatory testing such as a 24-hour urine collection for sodium and aldosterone while on a highsodium diet $[4,44]$. The ARR remains useful to screen for PA in patients taking most AHDs except Potassium-Sparing Diuretics (PSD) [41,44] Uncertainty regarding the optimal testing strategy for PA may warrant referral to an endocrinologist for confirmatory testing [4, 44]. Patients with PA often respond well to high doses of a Mineralocorticoid Receptor Antagonist (MRA) such as spironolactone, which may be superior to the less potent but more selective MRA eplerenone [45].

RAS is commonly identified in patients with resistant HTN, especially those with atherosclerotic vascular disease, and was previously considered to be the most common secondary cause of HTN $[31,46,47]$. Screening for RAS using renal artery imaging with ultrasound, CT or MRI is appropriate in many patients with resistant HTN, particularly with abdominal bruits, atherosclerotic vascular disease, elevated PRA, CKD, renal function deterioration on ACE inhibitor or ARB, renal size asymmetry, history of flash pulmonary edema or suspected fibromuscular dysplasia [47-50]. While the majority of RAS is caused by atherosclerosis, a minority of cases are due to fibromuscular dysplasia (particularly in women $<50$ years old) which may have a more robust response to renal artery intervention [47].

CKD with reduced Glomerular Filtration Rate (GFR) is a common

\begin{tabular}{|l|l|}
\hline Common secondary causes of HTN & Clues suggestive of specific etiology \\
\hline Obesity & Elevated body mass index and/or waist circumference, metabolic syndrome \\
\hline Renal artery stenosis & $\begin{array}{l}\text { Recurrent pulmonary edema, abdominal bruit, atherosclerotic vascular disease, renal size asymmetry, renal insufficiency, } \\
\text { elevated PRA }\end{array}$ \\
\hline Primary hyperaldosteronism & Hypokalemia, hypernatremia, metabolic alkalosis, elevated ARR and SAC, low PRA, edema \\
\hline Obstructive sleep apnea & Obesity, snoring, daytime sleepiness, witnessed apneas, nocturnal awakening \\
\hline Chronic kidney disease & Elevated creatinine and BUN, proteinuria, edema \\
\hline Uncommon secondary causes of HTN & Clues suggestive of specific etiology \\
\hline Cushing syndrome & Moon facies, central obesity, abdominal striae, hypokalemia, low PRA, hyperglycemia \\
\hline Pheochromocytoma & Intermittent BP surges, episodic spells of headache, diaphoresis, palpitations, tachycardia \\
\hline Hypercalcemia & Fatigue, gastrointestinal symptoms \\
\hline Aortic coarctation & Radial-femoral pulse delay, reduced femoral pulses, arm/leg BP discrepancy \\
\hline Thyroid disease & Fatigue, heat/cold intolerance, skin changes, tachycardia or bradycardia, eye signs, anxiety \\
\hline Intracranial tumor & Morning headache, neurological deficits \\
\hline
\end{tabular}

Table 1: Secondary causes of HTN. 


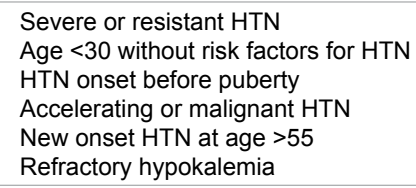

Table 2: Clues suggesting secondary HTN.

cause and consequence of resistant HTN [51]. Patients with CKD often have occult volume overload causing resistant HTN [4,52]. Patients with creatinine clearance $<30 \mathrm{ml} / \mathrm{min}$ may not respond to TD and require a more potent Loop Diuretic (LD) such as furosemide (given at least twice daily) or torsemide [4]. Further complicating the treatment of HTN in patients with CKD is the use of lower target BP goals to slow CKD progression, leading to higher rates of resistant HTN in patients with CKD $[1,4,51]$.

\section{Medical Treatment of Resistant HTN}

After excusion of secondary causes of HTN and optimization of lifestyle factors, many patients still have uncontrolled BP despite an optimal regimen of chlorthalidone/indapamide, CCB and ACEI or ARB. Patients with resistant essential HTN frequently have low renin with persistent sodium retention and occult volume overload, particularly elderly and/or African-American patients and those with CKD [53,54]. Confirming and reinforcing dietary sodium restriction is critical for these patients $[14,16]$. Increasing the intensity of existing diuretic therapy is a reasonable initial approach for most patients (especially with serum potassium $>4.5 \mathrm{mmol} / \mathrm{L}$ ), and is the most common intervention performed at many specialty HTN clinics $[17,19,55]$. Diuretic therapy (or ultrafiltration for patients on dialysis) should be intensified until the patient reaches a dry weight where further fluid loss leads to evidence of hypovolemia. For patients with persistently elevated BP on an optimized 3-drug AHD regimen, preferred secondline AHDs include MRA or Vasodilating Beta-Blockers (VBB) with AHDs such as sympatholytics or Vasodilators (VD) relegated to thirdline (Table 3).

AHD treatment can be tailored based on PRA, such that patients with suppressed PRA (PRA $<0.65-1 \mathrm{ng} / \mathrm{ml} / \mathrm{h}$, implying volume excess) receive intensified diuretic therapy, MRA and/or VD and patients with non-suppressed PRA ( $\geq 0.65-1 \mathrm{ng} / \mathrm{ml} / \mathrm{h}$, implying renin excess) receive intensified renin-angiotensin inhibition with ACE inhibitor, $A R B$, renin inhibitor and/or Beta-Blocker (BB) [53]. The cut-off between suppressed and non-suppressed PRA can vary by laboratory, but is generally $0.65-1 \mathrm{ng} / \mathrm{ml} / \mathrm{h}$. A small study of 77 patients with uncontrolled HTN showed improved systolic BP reduction $(29 \mathrm{mmHg}$ vs. $19 \mathrm{mmHg}$ ) using PRA-guided therapy compared to specialist care [56]. With PRA-guided therapy, physiologically ineffective AHDs can be withdrawn, such as ACE inhibitor/ARB/BB when PRA is low or diuretic/MRA when PRA is high $[53,56]$. A recent study of patients with uncontrolled HTN despite irbesartan $300 \mathrm{mg}$, amlodipine 5 $\mathrm{mg}$ and HCTZ $12.5 \mathrm{mg}$ showed improved BP control with addition of spironolactone \pm furosemide/amiloride compared to ramipril \pm bisoprolol [57]. This study was designed to show that diuretic therapy is more effective than renin-angiotensin inhibition in resistant HTN, but the results are limited by inadequate baseline dosing of amlodipine and HCTZ.

\section{Mineralocorticoid Receptor Antagonists}

For most patients with resistant HTN, a low-dose MRA (such as spironolactone $12.5-50 \mathrm{mg}$ daily) is an effective initial therapy, particularly with serum potassium $\leq 4.5 \mathrm{mmol} / \mathrm{L}$ (Figure 1 ) $[2,4,19]$.
Interest in spironolactone as add-on therapy for resistant HTN emerged more than a decade ago with the demonstration that lowdose spironolactone can produce robust BP lowering when added to a multi-drug AHT regimen in resistant HTN patients with or without PA [58]. Several observational studies, including an experience with 1141 patients from the ASCOT trial, have shown impressive BP reductions averaging $22 / 10 \mathrm{mmHg}$ with addition of low doses of spironolactone in resistant HTN patients without PA [59,60]. The randomized ASPIRANT study showed a much smaller $5.4 / 1 \mathrm{mmHg}$ reduction in ambulatory BP by spironolactone $25 \mathrm{mg}$ daily versus placebo, highlighting the importance of placebo control [61]. Hyperkalemia with MRA and other PSDs is more common in patients with diabetes, CKD and/or elevated baseline potassium levels; many patients with CKD (including selected oligoanuric dialysis patients) will tolerate MRA for resistant HTN [62-64].

In theory, patients with low PRA, high SAC or high ARR (implying excess sodium retention and/or aldosterone activity) should have greater BP reduction with MRA [53]. However, multiple studies have found MRA to be effective for resistant HTN regardless of PRA and SAC, suggesting that ARR may only predict response to MRA in untreated HTN patients [65-69]. MRA may lower BP by different mechanisms based on aldosterone status, producing diuresis in patients with hyperaldosteronism and vasorelaxation in patients without hyperaldosteronism [69].

We prefer MRA over non-MRA PSDs (i.e. amiloride) based on the adverse cardiovascular effects of aldosterone independent of renal sodium/potassium handling, warranting direct inhibition of its receptor $[39,69,70]$. An early randomized study in low-renin HTN showed superiority of amiloride $10 \mathrm{mg}$ over spironolactone $25 \mathrm{mg}$ for BP lowering [71]. However, a later study of HTN patients with high ARR showed similar BP lowering with amiloride $40 \mathrm{mg}$ and spironolactone $100 \mathrm{mg}$, and demonstrated that amiloride $40 \mathrm{mg}$ is needed to achieve maximum effect while spironolactone $100 \mathrm{mg}$ has minimal added

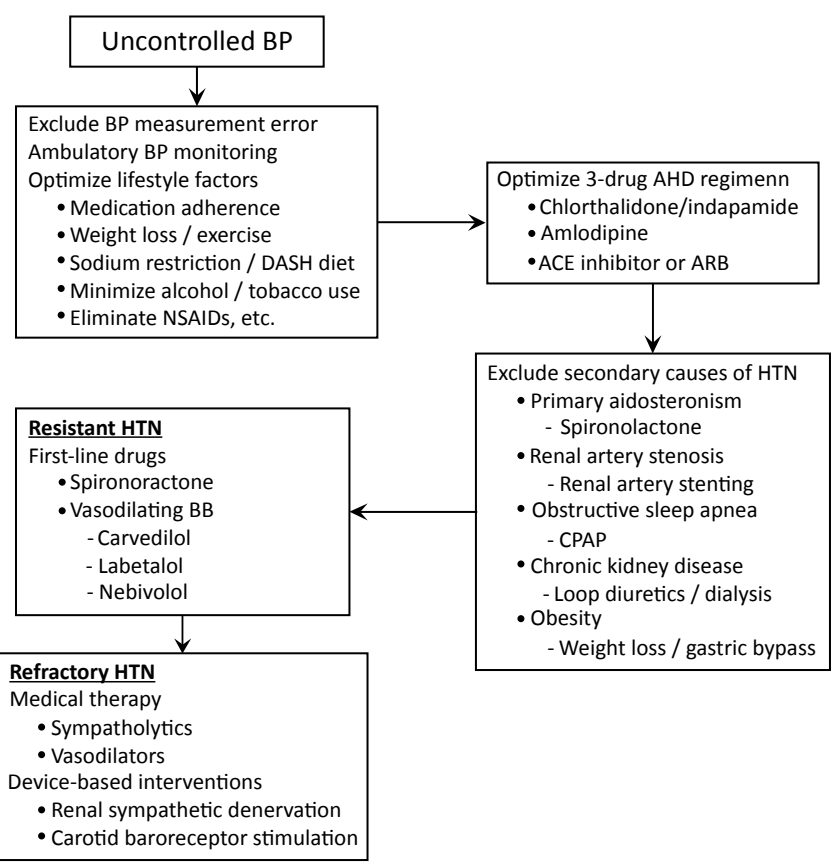

Figure 1: Approach to resistant HTN. 


\begin{tabular}{|c|c|c|c|c|c|}
\hline Drug & Class & Usual dose & Max dose & \# doses/day & Adverse effects \\
\hline Spironolactone & MRA & $12.5-50 \mathrm{mg}$ & $400 \mathrm{mg}$ & $1-2$ & Hyperkalemia, gynecomastia, renal insufficiency \\
\hline Eplerenone & MRA & $25-100 \mathrm{mg}$ & $200 \mathrm{mg}$ & $1-2$ & Hyperkalemia, renal insufficiency \\
\hline Carvedilol & ABB & $25-50 \mathrm{mg}$ & $100 \mathrm{mg}$ & 2 & Bradycardia, orthostasis, bronchospasm \\
\hline Carvedilol CR & ABB & $20-80 \mathrm{mg}$ & $80 \mathrm{mg}$ & 1 & Bradycardia, orthostasis, bronchospasm \\
\hline Labetalol & ABB & $200-800 \mathrm{mg}$ & $2400 \mathrm{mg}$ & $2-3$ & Bradycardia, orthostasis, bronchospasm \\
\hline Nebivolol & VBB & $5-10 \mathrm{mg}$ & $40 \mathrm{mg}$ & 1 & Bradycardia, headache \\
\hline Clonidine & A2A & $0.2-0.8 \mathrm{mg}$ & $2.4 \mathrm{mg}$ & $2-3$ & Fluid retention, orthostasis, sedation, bradycardia \\
\hline Guanfacine & $\mathrm{A} 2 \mathrm{~A}$ & $1-3 \mathrm{mg}$ & $4 \mathrm{mg}$ & 1 & Fluid retention, orthostasis, sedation, bradycardia \\
\hline Methyldopa & $\mathrm{A} 2 \mathrm{~A}$ & $250-1000 \mathrm{mg}$ & $3000 \mathrm{mg}$ & $2-3$ & Fluid retention, orthostasis, sedation, bradycardia \\
\hline Reserpine & Other & $0.05-0.1 \mathrm{mg}$ & $0.25 \mathrm{mg}$ & 1 & Fluid retention, orthostasis, sedation, depression \\
\hline Doxazosin & $A B$ & $2-8 \mathrm{mg}$ & $16 \mathrm{mg}$ & 1 & Fluid retention, orthostasis, tachycardia \\
\hline Terazosin & $A B$ & $2-10 \mathrm{mg}$ & $20 \mathrm{mg}$ & 1 & Fluid retention, orthostasis, tachycardia \\
\hline Hydralazine & VD & $25-100 \mathrm{mg}$ & $300 \mathrm{mg}$ & $2-3$ & Fluid retention, orthostasis, tachycardia \\
\hline Minoxidil & VD & $2.5-20 \mathrm{mg}$ & $80-100 \mathrm{mg}$ & $1-2$ & Fluid retention, orthostasis, tachycardia, hirsutism \\
\hline ISMN & VD & $30-120 \mathrm{mg}$ & $240 \mathrm{mg}$ & 1 & Fluid retention, orthostasis, tachycardia, headache \\
\hline
\end{tabular}

Table 3: AHDs for resistant HTN.

effect over $50 \mathrm{mg}$ [72]. The less-potent selective MRA eplerenone is effective in resistant HTN and avoids the anti-androgenic side effects of spironolactone but may have lower efficacy $[45,73]$. Investigational aldosterone synthase inhibitors show promise in early phase clinical trials of HTN and could prove to be a valuable alternative to MRA [74].

\section{Beta-blockers}

BB provide inferior cardiovascular prevention compared with firstline AHDs, likely due to unfavorable hemodynamic effects that produce a lesser degree of central aortic BP lowering than brachial BP lowering [75-77]. BB is superior for cardiovascular prevention compared with placebo and remains useful second-line AHDs [76]. BB is indicated for patients with resistant HTN and/or compelling indications such as coronary heart disease, heart failure or tachyarrhythmia $[1,4]$. Vasodilatory BB (VBB), including combined alpha/beta blockers $(\mathrm{ABB}$, i.e. labetalol/carvedilol) and nebivolol (which increases nitric oxide signaling), are the preferred BB for patients with HTN based on more favorable hemodynamic and metabolic effects (Figure 1) [77]. Patients with elevated PRA ( $\geq 0.65-1 \mathrm{ng} / \mathrm{ml} / \mathrm{h})$ and/or elevated resting heart rate $(>85 \mathrm{BPM})$ may have elevated adrenergic tone producing resistant HTN, and could benefit from VBB rather than MRA as their next AHD [53]. Evidence supporting improved HTN outcomes with VBB compared with other $\mathrm{BB}$ is scarce, but maximum doses of $\mathrm{ABB}$ may lower $\mathrm{BP}$ to a greater extent than other $\mathrm{BB}$ due to dose-dependent alpha blockade $[4,77,78]$. Carvedilol is a preferred VBB due to its low cost as well as proven safety and efficacy in multiple large trials, including direct comparison showing benefits over metoprolol [78-80]. Nebivolol is an effective AHD with the advantage of once-daily dosing and improved tolerability $[77,81]$.

\section{Refractory HTN}

Refractory HTN includes patients whose BP remains elevated despite use of $\geq 4$ AHDs, accounting for about $10 \%$ of resistant HTN patients referred to a speciality clinic [82]. These patients may respond poorly to spironolactone and display elevated resting Heart Rate (HR), implicating elevated sympathetic activity rather than sodium retention as the dominant pathophysiology [82]. Medical treatment of uncontrolled HTN despite an effective diuretic, CCB, ACE inhibitor or ARB, spironolactone and VBB remains challenging. Although third-line AHDs may be effective, device-based therapies such as renal sympathetic denervation, carotid baroreceptor stimulation or renal artery stenting should be considered (Figure 1) [83-85]. A thorough search for common and uncommon secondary causes of HTN (Table 1) should be considered and PRA-guided therapy may be useful $[4,53]$. Several novel AHDs in development could potentially find use in resistant HTN, but new drug development for resistant HTN is hindered by the significant placebo effect on BP and the availability of numerous inexpensive generic AHDs [61,74,86-88].

The third-line AHD classes for refractory HTN are sympatholytics and VD (Figure 1). These AHDs are prone to fluid retention with or without orthostasis, requiring a strong diuretic (often a LD); VD also produces reflex sympathetic activation and tachycardia. Clinical outcomes data are lacking with most of these AHDs despite clear antihypertensive efficacy. For PRA-guided therapy, low PRA $(<0.65-1$ $\mathrm{ng} / \mathrm{ml} / \mathrm{h}$ ) would favor use of a VD while elevated PRA $(\geq 0.65-1 \mathrm{ng} /$ $\mathrm{ml} / \mathrm{h}$ ) or elevated resting HR would favor use of a sympatholytic [53]. In selected patients with refractory HTN and persistently elevated PRA, the MRA could be replaced with an ARB or direct renin inhibitor, but a sympatholytic may be preferred given the modest BP lowering and increased adverse events seen with dual renin-angiotensin system blockade $[53,89,90]$. Triple therapy with MRA plus ACE inhibitor plus ARB or direct renin inhibitor is not recommended due to risk of hyperkalemia and renal dysfunction [4].

\section{Sympatholytics}

Sympatholytics include central alpha-2 agonists (A2A, i.e. clonidine/guanfacine/methyldopa) which reduce sympathetic activity and reserpine which reduces neuronal catecholamine release [91]. Clonidine is a potent and highly effective AHD despite a higher rate of adverse effects than first-line AHDs [92]. Clonidine's short duration of action poses a risk of rebound HTN after missed doses leading to chaotic BP control, but this can be overcome by use of a transdermal clonidine patch. The longer-acting and less potent A2A guanfacine requires once-daily dosing and has fewer side effects, but may be less effective [91]. Low-dose guanfacine $1 \mathrm{mg}$ daily failed to significantly improve office BP or mean ambulatory BP over placebo in a study of resistant HTN [86]. Methyldopa was effective in a small study of resistant HTN, but off-target adverse effects limit its use [91,93]. Reserpine is long-acting and effective at very low doses $(0.05-0.1 \mathrm{mg}$ daily) with established efficacy as add-on therapy in multiple large HTN trials; while psychiatric side effects can limit use of reserpine, these appear minor at low doses $[91,94]$. 


\section{Vasodilators}

VD include pure $A B$, long-acting nitrates, Endothelin Receptor Antagonists (ERA) and direct vasodilators (i.e. hydralazine/minoxidil) [91]. Long-acting $A B$ (i.e. terazosin/doxazosin) can be useful in patients who do not tolerate the $\mathrm{BB}$ effects of $\mathrm{ABB}$ and/or patients with prostatism, but an association between $\mathrm{AB}$ and adverse cardiovascular outcomes merits caution $[1,95,96]$. Long-acting nitrates such as Isosorbide Mononitrate (ISMN) can be useful in selected patients, especially isolated systolic HTN, coronary heart disease and/or heart failure $[97,98]$. Hydralazine can be highly effective at maximum dose, and the combination of hydralazine with long-acting nitrates is useful in patients with heart failure (particularly systolic dysfunction) [99]. Minoxidil is potent and long-acting, but produces hirsutism and prominent fluid retention. The ERA darusentan is one of the few AHDs evaluated in placebo-controlled studies for resistant HTN. Darusentan $50-300 \mathrm{mg}$ daily reduced BP in resistant $\mathrm{HTN}$ by $17-18 / 10-11 \mathrm{mmHg}$ (vs. 9/5 $\mathrm{mmHg}$ with placebo) but increased the risk of fluid retention [87]. In patients with resistant HTN, darusentan 50-300 mg daily was effective for reducing mean ambulatory $\mathrm{BP}(9 \mathrm{mmHg}$ vs. $4 \mathrm{mmHg}$ with guanfacine $1 \mathrm{mg}$ daily and $2 \mathrm{mmHg}$ with placebo) despite similar inoffice $\mathrm{BP}$ reduction and a higher rate of adverse effects [86].

\section{Device-based Therapy and Resistant HTN}

Combination pharmacologic therapy is currently the preferred approach for most patients with resistant HTN (Figure 1). Nonetheless, an important minority of patients have refractory HTN and/or a correctible cause of HTN that can be addressed using novel devicebased therapies. Renal artery angioplasty/stenting has been evaluated in large-scale clinical trials of patients with atherosclerotic RAS [85]. For patients with resistant essential HTN, catheter-based renal sympathetic denervation appears to have favorable efficacy and safety $[83,100]$. Other novel therapies including carotid baroreceptor stimulation (CBS) are still undergoing evaluation $[84,88]$.

Renal Artery Angioplasty/Stenting (RAAS) has been available for many years, but large-scale clinical trials comparing RAAS with Optimal Medical Therapy (OMT) in atherosclerotic RAS have only occurred recently $[47,85,101,102]$. RAAS is highly effective for RAS due to FMD and remains standard therapy these patients $[47,50]$. However, the results of recent trials have cast doubt on the routine use of RAAS in atherosclerotic RAS $[85,102]$. The large-scale ASTRAL trial randomized 806 patients with atherosclerotic RAS to RAAS + OMT vs. OMT alone and found no significant differences in BP control, renal events, cardiovascular events or death during up to 5 years followup [102]. A meta-analysis including 1208 patients confirmed these findings, showing no significant benefit for any major outcome [85]. Anecdotally, there are patients who benefit substantially from RAAS for atherosclerotic RAS. Elevated PRA, renal function deterioration on ACE inhibitor or ARB, renal size asymmetry, history of flash pulmonary edema, accelerating or refractory HTN may identify patients who are more likely to benefit from RAAS $[47,49,50]$. However, those patients with resistant essential HTN and incidental RAS may not benefit from RAAS. The rate of procedural complications from RAAS in ASTRAL was $9 \%$, further arguing in favor of careful patient selection [102].

Increased renal sympathetic activity is common in patients with HTN, with hyperactivity of both efferent and afferent renal sympathetic nerves contributing to elevated BP $[100,103,104]$. Newly-developed minimally-invasive techniques using catheter-based radiofrequency ablation to abolish renal sympathetic nerve activity have been compared with medical therapy in resistant HTN $[83,100]$. The Symplicity HTN-
2 trial randomized 106 patients with resistant essential HTN to renal denervation (RD) using the Simplicity catheter system in addition to prior AHDs which were unchanged for 6 months (followed by crossover of all untreated patients to RD), and demonstrated a 33/11 $\mathrm{mmHg}$ greater $\mathrm{BP}$ reduction with $\mathrm{RD}$ at 6 months [83]. A sustained $28 / 10 \mathrm{mmHg}$ BP reduction at 1 year was seen in patients initially randomized to $\mathrm{RD}$, plus a $24 / 8 \mathrm{mmHg} \mathrm{BP}$ reduction at 6 months in patients who crossed over to RD after initial medical therapy [100]. A systematic review of published RD studies confirmed sustained $\mathrm{BP}$ reductions of 18-36/9-15 mmHg over 12 months with infrequent complications [103]. Patients remained on multiple AHDs after RD, so $\mathrm{RD}$ should be considered an effective add-on treatment for resistant or refractory HTN rather than a cure $[83,100]$.

Carotid sinus baroreceptors regulate BP via modulation of sympathetic tone, allowing simulation of these baroreceptors to reduce sympathetic activity and BP $[105,106]$. Observational studies of the surgically-implanted Rheos CBS system in resistant HTN showed improvements in $\mathrm{BP}$ over long-term follow-up, with a response rate of $76 \%$, a mean $\mathrm{BP}$ reduction of $35 / 16 \mathrm{mmHg}$, and a $55 \%$ rate of achieving BP goals $[107,108]$. A subsequent randomized controlled study of CBS failed to meet its primary efficacy endpoint of patients achieving $\geq$ $10 \mathrm{mmHg}$ reduction in systolic BP at 6 months (54\% with the Rheos device vs. $46 \%$ with control), despite a greater systolic BP reduction (16 $\mathrm{mmHg}$ vs. $9 \mathrm{mmHg}$ ) at 6 months and mean systolic BP reduction of 25 $\mathrm{mmHg}$ at 1 year [84]. For initial CBS responders, the mean systolic BP reduction was $44 \mathrm{mmHg}$ and $88 \%$ of patients had a sustained response [84]. The risk of procedural complications from surgical CBS device implantation did not meet the primary safety endpoint [84].

\section{Conclusions}

Resistant HTN is a common clinical problem with a rising prevalence due to increasing rates of risk factors such as older age, obesity, diabetes and CKD. While most patients have resistant essential HTN and/or other identifiable reasons for uncontrolled HTN, a significant number have treatable secondary etiologies such as obesity, OSA, RAS, PA or CKD. We reserve the term resistant $\mathrm{HTN}$ for patients whose $\mathrm{BP}$ remains uncontrolled despite lifestyle intervention plus 3 first-line AHDs, ideally chlorthalidone or indapamide plus a CCB and an ACE inhibitor or ARB. The pathophysiology of resistant HTN involves occult volume overload and/or sympathetic hyperactivity, and most patients will respond to diuretic intensification plus spironolactone and/or VBB as preferred second-line agents. For patients with HTN refractory to this combination of AHDs, third-line drugs such as sympatholytics or VD can be effective but investigational device-based therapies should be considered. The device-based antihypertensive therapies furthest along in clinical evaluation are RD and CBS, along with RAAS for selected patients with RAS; at this time RD appears the most promising in terms of safety and efficacy. Critical areas of ongoing research include patient selection for these therapies and an evaluation of their risks and benefits. Well-controlled trials will be needed to compare different second- and third-line AHDs with each other and to compare AHD alone with AHD plus device-based therapies in this high-risk patient population.

\section{References}

1. Chobanian AV, Bakris GL, Black HR, Cushman WC, Green LA, et al. (2003) The Seventh Report of the Joint National Committee on Prevention, Detection, Evaluation, and Treatment of High Blood Pressure: the JNC 7 report. JAMA 289: $2560-2572$.

2. Mancia G, De Backer G, Dominiczak A, Cifkova R, Fagard R, et al. (2007) 2007 Guidelines for the Management of Arterial Hypertension: The Task Force for the Management of Arterial Hypertension of the European Society 
of Hypertension (ESH) and of the European Society of Cardiology (ESC). J Hypertens 25: 1105-1187.

3. Guo F, He D, Zhang W, Walton RG (2012) Trends in prevalence, awareness, management, and control of hypertension among United States adults, 1999 to 2010. J Am Coll Cardiol 60: 599-606.

4. Calhoun DA, Jones D, Textor S, Goff DC, Murphy TP, et al. (2008) Resistant hypertension: diagnosis, evaluation, and treatment: a scientific statement from the American Heart Association Professional Education Committee of the Council for High Blood Pressure Research. Circulation 117: e510-e526.

5. Roberie DR, Elliott WJ (2012) What is the prevalence of resistant hypertension in the United States? Curr Opin Cardiol 27: 386-391.

6. Kumbhani DJ, Steg PG, Cannon CP, Eagle KA, Smith SC Jr, et al. (2012) Resistant hypertension: a frequent and ominous finding among hypertensive patients with atherothrombosis. Eur Heart J.

7. Barochiner J, Alfie J, Aparicio LS, Cuffaro PE, Rada MA, et al. (2012) Prevalence and Clinical Profile of Resistant Hypertension among Treated Hypertensive Subjects. Clin Exp Hypertens.

8. de la Sierra A, Segura J, Banegas JR, Gorostidi M, de la Cruz JJ, et al. (2011) Clinical features of 8295 patients with resistant hypertension classified on the basis of ambulatory blood pressure monitoring. Hypertension 57: 898-902.

9. Salles GF, Cardoso CR, Muxfeldt ES (2008) Prognostic influence of office and ambulatory blood pressures in resistant hypertension. Arch Intern Med 168 : 2340-2346.

10. Bramlage P, Pittrow D, Wittchen HU, Kirch W, Boehler S, et al. (2004) Hypertension in overweight and obese primary care patients is highly prevalen and poorly controlled. Am J Hypertens 17: 904-910.

11. Aucott L, Poobalan A, Smith WC, Avenell A, Jung R, et al. (2005) Effects of weight loss in overweight/obese individuals and long-term hypertension outcomes: a systematic review. Hypertension 45: 1035-1041.

12. Adams ST, Salhab M, Hussain ZI, Miller GV, Leveson SH (2012) Obesityrelated hypertension and its remission following gastric bypass surgery - A review of the mechanisms and predictive factors. Blood Press.

13. Dimeo F, Pagonas N, Seibert F, Arndt R, Zidek W, et al. (2012) Aerobic exercise reduces blood pressure in resistant hypertension. Hypertension 60: 653-658.

14. Agarwal R (2012) Resistant hypertension and the neglected antihypertensive: sodium restriction. Nephrol Dial Transplant 27: 4041-4045.

15. Vollmer WM, Sacks FM, Ard J, Appel LJ, Bray GA, et al. (2001) Effects of diet and sodium intake on blood pressure: subgroup analysis of the DASH-sodium trial. Ann Intern Med 135: 1019-1028.

16. Pimenta E, Gaddam KK, Oparil S, Aban I, Husain S, et al. (2009) Effects of dietary sodium reduction on blood pressure in subjects with resistant hypertension: results from a randomized trial. Hypertension 54: 475-481.

17. Garg JP, Elliott WJ, Folker A, Izhar M, Black HR, et al. (2005) Resistant hypertension revisited: a comparison of two university-based cohorts. Am J Hypertens 18: 619-626.

18. Irvin MR, Shimbo D, Mann DM, Reynolds K, Krousel-Wood M, et al. (2012) Prevalence and correlates of low medication adherence in apparent treatmentresistant hypertension. J Clin Hypertens (Greenwich) 14: 694-700.

19. Krause T, Lovibond K, Caulfield M, McCormack T, Williams B, et al. (2011) Management of hypertension: summary of NICE guidance. BMJ 343: d4891.

20. Nixon RM, Müller E, Lowy A, Falvey H (2009) Valsartan vs. other angiotensin I receptor blockers in the treatment of hypertension: a meta-analytical approach. Int J Clin Pract 63: 766-775.

21. Dahlöf B, Sever PS, Poulter NR, Wedel H, Beevers DG, et al. (2005) Prevention of cardiovascular events with an antihypertensive regimen of amlodipine adding perindopril as required versus atenolol adding bendroflumethiazide as required, in the Anglo-Scandinavian Cardiac Outcomes Trial-Blood Pressure Lowering Arm (ASCOT-BPLA): a multicentre randomised controlled trial. Lancet 366: 895-906.

22. ALLHAT Officers and Coordinators for the ALLHAT Collaborative Research Group The Antihypertensive and Lipid-Lowering Treatment to Prevent Heart Attack Trial (2002) Major outcomes in high-risk hypertensive patients randomized to angiotensin-converting enzyme inhibitor or calcium channe blocker vs diuretic: The Antihypertensive and Lipid-Lowering Treatment to Prevent Heart Attack Trial (ALLHAT). JAMA 288: 2981-2997.
23. Jamerson K, Weber MA, Bakris GL, Dahlöf B, Pitt B et al. (2008) Benazepril plus amlodipine or hydrochlorothiazide for hypertension in high-risk patients. $N$ Engl J Med 359: 2417-2428.

24. Ernst ME, Carter BL, Zheng S, Grimm RH Jr (2010) Meta-analysis of doseresponse characteristics of hydrochlorothiazide and chlorthalidone: effects on systolic blood pressure and potassium. Am J Hypertens 23: 440-446.

25. Baguet JP, Legallicier B, Auquier P, Robitail S (2007) Updated meta-analytica approach to the efficacy of antihypertensive drugs in reducing blood pressure. Clin Drug Investig 27: 735-753.

26. Al Badarin FJ, Abuannadi MA, Lavie CJ, O'Keefe JH (2011) Evidencebased diuretic therapy for improving cardiovascular prognosis in systemic hypertension. Am J Cardiol 107: 1178-1184.

27. Beckett NS, Peters R, Fletcher AE, Staessen JA, Liu L, et al. (2008) Treatment of hypertension in patients 80 years of age or older. N Engl J Med 358: 1887 1898.

28. Roush GC, Holford TR, Guddati AK (2012) Chlorthalidone compared with hydrochlorothiazide in reducing cardiovascular events: systematic review and network meta-analyses. Hypertension 59: 1110-1117.

29. Messerli FH, Makani H, Benjo A, Romero J, Alviar C, et al. (2011) Antihypertensive efficacy of hydrochlorothiazide as evaluated by ambulatory blood pressure monitoring: a meta-analysis of randomized trials. J Am Coll Cardiol 57: 590-600

30. Segura J, Cerezo C, Garcia-Donaire JA, Schmieder RE, Praga M, et al. (2011) Validation of a therapeutic scheme for the treatment of resistant hypertension. J Am Soc Hypertens 5: 498-504.

31. Anderson GH Jr, Blakeman N, Streeten DH (1994) The effect of age on prevalence of secondary forms of hypertension in 4429 consecutively referred patients. J Hypertens 12: 609-615.

32. Pedrosa RP, Drager LF, Gonzaga CC, Sousa MG, de Paula LK, et al. (2011) Obstructive sleep apnea: the most common secondary cause of hypertension associated with resistant hypertension. Hypertension 58: 811-817.

33. Logan AG, Perlikowski SM, Mente A, Tisler A, Tkacova R, et al. (2001) High prevalence of unrecognized sleep apnoea in drug-resistant hypertension. $J$ Hypertens 19: 2271-2277.

34. Gonçalves SC, Martinez D, Gus M, de Abreu-Silva EO, Bertoluci C, et al. (2007) Obstructive sleep apnea and resistant hypertension: a case-contro study. Chest 132: 1858-1862.

35. Pimenta E, Stowasser M, Gordon RD, Harding SM, Batlouni M, et al. (2013) INCREASED DIETARY SODIUM IS RELATED TO SEVERITY OF OBSTRUCTIVE SLEEP APNEA IN PATIENTS WITH RESISTANT HYPERTENSION AND HYPERALDOSTERONISM. Chest.

36. Kalil GZ, Haynes WG (2012) Sympathetic nervous system in obesity-related hypertension: mechanisms and clinical implications. Hypertens Res 35: 4-16.

37. Whaley-Connell A, Johnson MS, Sowers JR (2010) Aldosterone: role in the cardiometabolic syndrome and resistant hypertension. Prog Cardiovasc Dis 52 401-409.

38. Grassi G, Facchini A, Trevano FQ, Dell'Oro R, Arenare F, et al (2005) Obstructive sleep apnea-dependent and -independent adrenergic activation in obesity. Hypertension 46: 321-325.

39. Dudenbostel T, Calhoun DA (2012) Resistant hypertension, obstructive sleep apnoea and aldosterone. J Hum Hypertens 26: 281-287.

40. Lozano L, Tovar JL, Sampol G, Romero O, Jurado MJ, et al. (2010) Continuous positive airway pressure treatment in sleep apnea patients with resistan hypertension: a randomized, controlled trial. J Hypertens 28: 2161-2168.

41. Gallay BJ, Ahmad S, Xu L, Toivola B, Davidson RC (2001) Screening for primary aldosteronism without discontinuing hypertensive medications: plasma aldosterone-renin ratio. Am J Kidney Dis 37: 699-705.

42. Eide IK, Torjesen PA, Drolsum A, Babovic A, Lilledahl NP (2004) Low-renin status in therapy-resistant hypertension: a clue to efficient treatment. J Hypertens 22: 2217-2226.

43. Douma S, Petidis K, Doumas M, Papaefthimiou P, Triantafyllou A, et al. (2008) Prevalence of primary hyperaldosteronism in resistant hypertension: a retrospective observational study. Lancet 371: 1921-1926.

44. Funder JW, Carey RM, Fardella C, Gomez-Sanchez CE, Mantero F, et al. 
(2008) Case detection, diagnosis, and treatment of patients with primary aldosteronism: an endocrine society clinical practice guideline. J Clin Endocrino Metab 93: 3266-3281.

45. Parthasarathy HK, Ménard J, White WB, Young WF Jr, Williams GH, et al (2011) A double-blind, randomized study comparing the antihypertensive effect of eplerenone and spironolactone in patients with hypertension and evidence of primary aldosteronism. J Hypertens 29: 980-990.

46. Aqel RA, Zoghbi GJ, Baldwin SA, Auda WS, Calhoun DA, et al. (2003) Prevalence of renal artery stenosis in high-risk veterans referred to cardiac catheterization. J Hypertens 21: 1157-1162.

47. Baumgartner I, Lerman LO (2011) Renovascular hypertension: screening and modern management. Eur Heart J 32: 1590-1598.

48. Leiner T, de Haan MW, Nelemans PJ, van Engelshoven JM, Vasbinder GB (2005) Contemporary imaging techniques for the diagnosis of renal artery stenosis. Eur Radiol 15: 2219-2229.

49. Messerli FH, Bangalore S, Makani H, Rimoldi SF, Allemann Y, et al. (2011) Flash pulmonary oedema and bilateral renal artery stenosis: the Pickering syndrome. Eur Heart J 32: 2231-2235.

50. Hirsch AT, Haskal ZJ, Hertzer NR, Bakal CW, Creager MA, et al. (2006) ACC/ AHA 2005 Practice Guidelines for the management of patients with peripheral arterial disease (lower extremity, renal, mesenteric, and abdominal aortic): a collaborative report from the American Association for Vascular Surgery/ Society for Vascular Surgery, Society for Cardiovascular Angiography and Interventions, Society for Vascular Medicine and Biology, Society of Interventional Radiology, and the ACC/AHA Task Force on Practice Guidelines (Writing Committee to Develop Guidelines for the Management of Patients With Peripheral Arterial Disease): endorsed by the American Association of Cardiovascular and Pulmonary Rehabilitation; National Heart, Lung, and Blood Institute; Society for Vascular Nursing; TransAtlantic Inter-Society Consensus; and Vascular Disease Foundation. Circulation 113: e463-e654.

51. Saelen MG, Prøsch LK, Gudmundsdottir H, Dyrbekk D, Helge Hunderi O, et al. (2005) Controlling systolic blood pressure is difficult in patients with diabetic kidney disease exhibiting moderate-to-severe reductions in renal function. Blood Press 14: 170-176.

52. Verdalles U, de Vinuesa SG, Goicoechea M, Quiroga B, Reque J, et al. (2012) Utility of bioimpedance spectroscopy (BIS) in the management of refractory hypertension in patients with chronic kidney disease (CKD). Nephrol Dial Transplant 27: iv31-35.

53. Laragh JH, Sealey JE (2011) The plasma renin test reveals the contribution of body sodium-volume content $(V)$ and renin-angiotensin $(R)$ vasoconstriction to long-term blood pressure. Am J Hypertens 24: 1164-1180.

54. Boudville N, Ward S, Benaroia M, House AA (2005) Increased sodium intake correlates with greater use of antihypertensive agents by subjects with chronic kidney disease. Am J Hypertens 18: 1300-1305.

55. Taler SJ, Textor SC, Augustine JE (2002) Resistant hypertension: comparing hemodynamic management to specialist care. Hypertension 39: 982-988.

56. Egan BM, Basile JN, Rehman SU, Davis PB, Grob CH 3rd, et al. (2009) Plasma Renin test-guided drug treatment algorithm for correcting patients with treated but uncontrolled hypertension: a randomized controlled trial. Am J Hypertens 22: $792-801$

57. Bobrie G, Frank M, Azizi M, Peyrard S, Boutouyrie P, et al. (2012) Sequentia nephron blockade versus sequential renin-angiotensin system blockade in resistant hypertension: a prospective, randomized, open blinded endpoint study. J Hypertens 30: 1656-1664.

58. Nishizaka MK, Zaman MA, Calhoun DA (2003) Efficacy of low-dose spironolactone in subjects with resistant hypertension. Am J Hypertens 16: 925-930

59. Marrs JC (2010) Spironolactone management of resistant hypertension. Ann Pharmacother 44: 1762-1769.

60. Chapman N, Dobson J, Wilson S, Dahlöf B, Sever PS, et al. (2007) Effect of spironolactone on blood pressure in subjects with resistant hypertension. Hypertension 49: 839-845.

61. Václavík J, Sedlák R, Plachy M, Navrátil K, Plásek J, et al. (2011) Addition of spironolactone in patients with resistant arterial hypertension (ASPIRANT): a randomized, double-blind, placebo-controlled trial. Hypertension 57: 10691075.
62. Pisoni R, Acelajado MC, Cartmill FR, Dudenbostel T, Dell'Italia LJ, et al. (2012) Long-term effects of aldosterone blockade in resistant hypertension associated with chronic kidney disease. J Hum Hypertens 26: 502-506.

63. Gross E, Rothstein M, Dombek S, Juknis HI (2005) Effect of spironolactone on blood pressure and the renin-angiotensin-aldosterone system in oligo-anuric hemodialysis patients. Am J Kidney Dis 46: 94-101.

64. Shavit L, Neykin D, Lifschitz M, Slotki I (2011) Effect of eplerenone on blood pressure and the renin-angiotensin-aldosterone system in oligo-anuric chronic hemodialysis patients - a pilot study. Clin Nephrol 76: 388-395.

65. de Souza F, Muxfeldt E, Fiszman R, Salles G (2010) Efficacy of spironolactone therapy in patients with true resistant hypertension. Hypertension 55: 147-152.

66. Parthasarathy HK, Alhashmi K, McMahon AD, Struthers AD, McInnes GT, et al. (2010) Does the ratio of serum aldosterone to plasma renin activity predic the efficacy of diuretics in hypertension? Results of RENALDO. J Hypertens 28: 170-177.

67. Ubaid-Girioli S, Adriana de Souza L, Yugar-Toledo JC, Martins LC, FerreiraMelo S, et al. (2009) Aldosterone excess or escape: Treating resistant hypertension. J Clin Hypertens (Greenwich) 11: 245-252.

68. Mahmud A, Mahgoub M, Hall M, Feely J (2005) Does aldosterone-torenin ratio predict the antihypertensive effect of the aldosterone antagonis spironolactone? Am J Hypertens 18: 1631-1635.

69. Gaddam K, Corros C, Pimenta E, Ahmed M, Denney T, et al. (2010) Rapid reversal of left ventricular hypertrophy and intracardiac volume overload in patients with resistant hypertension and hyperaldosteronism: a prospective clinical study. Hypertension 55: 1137-1142.

70. Shibata H, Itoh H (2012) Mineralocorticoid receptor-associated hypertension and its organ damage: clinical relevance for resistant hypertension. Am J Hypertens 25: 514-523.

71. Saha C, Eckert GJ, Ambrosius WT, Chun TY, Wagner MA, et al. (2005) Improvement in blood pressure with inhibition of the epithelial sodium channel in blacks with hypertension. Hypertension 46: 481-487.

72. Hood SJ, Taylor KP, Ashby MJ, Brown MJ (2007) The spironolactone amiloride, losartan, and thiazide (SALT) double-blind crossover trial in patients with low-renin hypertension and elevated aldosterone-renin ratio. Circulation 116: 268-275.

73. Calhoun DA, White WB (2008) Effectiveness of the selective aldosterone blocker, eplerenone, in patients with resistant hypertension. J Am Soc Hypertens 2: 462-468.

74. Calhoun DA, White WB, Krum H, Guo W, Bermann G, et al. (2011) Effects of a novel aldosterone synthase inhibitor for treatment of primary hypertension: results of a randomized, double-blind, placebo- and active-controlled phase 2 trial. Circulation 124: 1945-1955.

75. Lindholm LH, Carlberg B, Samuelsson O (2005) Should beta blockers remain first choice in the treatment of primary hypertension? A meta-analysis. Lance 366: 1545-1553.

76. Wiysonge CS, Bradley HA, Volmink J, Mayosi BM, Mbewu A, et al. (2012) Beta-blockers for hypertension. Cochrane Database Syst Rev 11: CD002003.

77. Ram CV (2010) Beta-blockers in hypertension. Am J Cardiol 106: 1819-1825.

78. Leonetti G, Egan CG (2012) Use of carvedilol in hypertension: an update. Vasc Health Risk Manag 8: 307-322.

79. Poole-Wilson PA, Swedberg K, Cleland JG, Di Lenarda A, Hanrath P, et al. (2003) Comparison of carvedilol and metoprolol on clinical outcomes in patients with chronic heart failure in the Carvedilol Or Metoprolol European Trial (COMET): randomised controlled trial. Lancet 362: 7-13

80. Bakris GL, Fonseca V, Katholi RE, McGill JB, Messerli FH, et al. (2004) Metabolic effects of carvedilol vs metoprolol in patients with type 2 diabetes mellitus and hypertension: a randomized controlled trial. JAMA 292: 2227 2236

81. Van Bortel LM, Fici F, Mascagni F (2008) Efficacy and tolerability of nebivolo compared with other antihypertensive drugs: a meta-analysis. Am J Cardiovasc Drugs 8: 35-44.

82. Acelajado MC, Pisoni R, Dudenbostel T, Dell'Italia LJ, Cartmill F, et al. (2012) Refractory hypertension: definition, prevalence, and patient characteristics. $J$ Clin Hypertens (Greenwich) 14: 7-12. 
83. Symplicity HTN-2 Investigators, Esler MD, Krum H, Sobotka PA, Schlaich $\mathrm{MP}$, et al. (2010) Renal sympathetic denervation in patients with treatmentresistant hypertension (The Symplicity HTN-2 Trial): a randomised controlled trial. Lancet 376: 1903-1909.

84. Bisognano JD, Bakris G, Nadim MK, Sanchez L, Kroon AA, et al. (2011) Baroreflex activation therapy lowers blood pressure in patients with resistan hypertension: results from the double-blind, randomized, placebo-controlled rheos pivotal trial. J Am Coll Cardiol 58: 765-773.

85. Kumbhani DJ, Bavry AA, Harvey JE, de Souza R, Scarpioni R, et al. (2011) Clinical outcomes after percutaneous revascularization versus medica management in patients with significant renal artery stenosis: a meta-analysis of randomized controlled trials. Am Heart J 161: 622-630.

86. Bakris GL, Lindholm LH, Black HR, Krum H, Linas S, et al. (2010) Divergent results using clinic and ambulatory blood pressures: report of a darusentanresistant hypertension trial. Hypertension 56: 824-830.

87. Weber MA, Black H, Bakris G, Krum H, Linas S, et al. (2009) A selective endothelin-receptor antagonist to reduce blood pressure in patients with treatment-resistant hypertension: a randomised, double-blind, placebocontrolled trial. Lancet 374: 1423-1431.

88. Laurent S, Schlaich M, Esler M (2012) New drugs, procedures, and devices for hypertension. Lancet 380: 591-600.

89. Parving HH, Brenner BM, McMurray JJ, de Zeeuw D, Haffner SM, et al. (2012) Cardiorenal end points in a trial of aliskiren for type 2 diabetes. N Engl J Med 367: 2204-2213.

90. ONTARGET Investigators, Yusuf S, Teo KK, Pogue J, Dyal L, et al. (2008) Telmisartan, ramipril, or both in patients at high risk for vascular events. N Engl J Med 358: 1547-1559.

91. Slim HB, Black HR, Thompson PD (2011) Older blood pressure medications-do they still have a place? Am J Cardiol 108: 308-316.

92. Materson BJ, Reda DJ, Cushman WC, Massie BM, Freis ED, et al. (1993) Singledrug therapy for hypertension in men. A comparison of six antihypertensive agents with placebo. The Department of Veterans Affairs Cooperative Study Group on Antihypertensive Agents. N Engl J Med 328: 914-921.

93. Sermswan A, Archawarak N (2003) Methyldopa supplement for resistan essential hypertension: a prospective randomized placebo control crossover study. J Med Assoc Thai 86: 1156-1161.

94. Fraser HS (1996) Reserpine: a tragic victim of myths, marketing, and fashionable prescribing. Clin Pharmacol Ther 60: 368-373.

95. Nickel JC, Sander S, Moon TD (2008) A meta-analysis of the vascular-related safety profile and efficacy of alpha-adrenergic blockers for symptoms related to benign prostatic hyperplasia. Int J Clin Pract 62: 1547-1559.

96. (2000) Major cardiovascular events in hypertensive patients randomized to doxazosin vs chlorthalidone: the antihypertensive and lipid-lowering treatment to prevent heart attack trial (ALLHAT). ALLHAT Collaborative Research Group JAMA 283: 1967-1975.

97. Stokes GS, Bune AJ, Huon N, Barin ES (2005) Long-term effectiveness of extended-release nitrate for the treatment of systolic hypertension. Hypertension 45: 380-384.

98. Stokes GS (2006) Nitrates as adjunct hypertensive treatment. Curr Hypertens Rep 8: 60-68.

99. Cohn JN, Archibald DG, Ziesche S, Franciosa JA, Harston WE, et al. (1986) Effect of vasodilator therapy on mortality in chronic congestive heart failure. Results of a Veterans Administration Cooperative Study. N Engl J Med 314 1547-1552.

100. Esler MD, Krum H, Schlaich M, Schmieder RE, Böhm M et al. (2012) Renal sympathetic denervation for treatment of drug-resistant hypertension: oneyear results from the Symplicity HTN-2 randomized, controlled trial. Circulation 126: $2976-2982$.

101. Nordmann AJ, Woo K, Parkes R, Logan AG (2003) Balloon angioplasty or medical therapy for hypertensive patients with atherosclerotic renal artery stenosis? A meta-analysis of randomized controlled trials. Am J Med 114: 44 50 .

102. ASTRAL Investigators, Wheatley K, Ives N, Gray R, Kalra PA, et al. (2009) Revascularization versus medical therapy for renal-artery stenosis. $\mathrm{N}$ Engl $J$ Med 361: 1953-1962.

103. Gosain P, Garimella PS, Hart PD, Agarwal R (2013) Renal sympathetic denervation for treatment of resistant hypertension: a systematic review. J Clin Hypertens (Greenwich) 15: 75-84.

104. Schmieder RE, Redon J, Grassi G, Kjeldsen SE, Mancia G, et al. (2012) ESH position paper: renal denervation - an interventional therapy of resistan hypertension. J Hypertens 30: 837-841.

105. Heusser K, Tank J, Engeli S, Diedrich A, Menne J, et al (2010) Carotid baroreceptor stimulation, sympathetic activity, baroreflex function, and blood pressure in hypertensive patients. Hypertension 55: 619-626.

106. Doumas M, Faselis C, Tsioufis C, Papademetriou V (2012) Carotid baroreceptor activation for the treatment of resistant hypertension and heart failure. Curr Hypertens Rep 14: 238-246.

107. Scheffers IJ, Kroon AA, Schmidli J, Jordan J, Tordoir JJ, et al. (2010) Nove baroreflex activation therapy in resistant hypertension: results of a European multi-center feasibility study. J Am Coll Cardiol 56: 1254-1258.

108. Bakris GL, Nadim MK, Haller H, Lovett EG, Schafer JE, et al. (2012) Baroreflex activation therapy provides durable benefit in patients with resistant hypertension: results of long-term follow-up in the Rheos Pivotal Trial. J Am Soc Hypertens 6: 152-158. 